\title{
THE LIGHT GRADIENTS INSIDE SOYBEAN LEAVES AND THEIR EFFECT ON THE CURVATURE FACTOR OF THE LIGHT RESPONSE CURVES OF PHOTOSYNTHESIS
}

\author{
TANIA JUNE \\ BIOTROP ICSEA, SEAMEO BIOTROP, BTIC Building, \\ Jl. Raya Tajur Km. 6 Bogor, Indonesia; email: taniajune@biotrop.org; and \\ Laboratory of Agrometeorology, Bogor Agricultural University, Bogor, Indonesia
}

\begin{abstract}
Light gradients within leaves are not included in the model of Farquhar, although a steep light gradient does exist within leaves. For a bifacial leaf, the model shows good agreement with measured data, but for an isobilateral leaf the model may underestimate photosynthesis measured by conventional gas exchange. Isobilateral leaves easily developed when plants were grown in growth chambers where some light were reflected from the growth chamber metal base onto the lower surface of the leaves during growth, resulting in adjustment of the photosynthetic capacity inside the leaves. This could also happen in the field when canopy is very sparse and lower surface of leaves was exposed to reflected light from soil surface. Complications occurred when fitting the light response curves of the electron transport rate, due to the interaction between the quantum yield of electron transport $\left(a_{2}\right)$ and the curvature factor $(\Theta)$. It is suspected that there may be an interaction with the light gradient within the leaf. This manuscript discusses the effect of a light gradient inside a soybean leaf on the estimation of $\Theta$. It is shown in the manuscript how the light curves of the isobilateral leaves (at different degree) responded when measured using conventional gas exchange and how it affected the estimation of $\Theta$ and the electron transport capacity, $J_{\max }$. An experiment was conducted to prove the hypothesis that this "out of ordinary" estimate of $\Theta$ (and hence $J_{\max }$ ) was due to the unmatched distribution of photosynthetic capacity with distribution of absorbed light.
\end{abstract}

Keywords : light gradient / photosynthetic capacity $\left(J_{\max }\right) /$ curvature factor $(\Theta) /$ gas exchange

\section{INTRODUCTION}

Anatomically, there are two types of leaves, bifacial and isobilateral. Bifacial leaves have different adaxial and abaxial surfaces (i.e. top and bottom), while in isobilateral leaves these differences do not exist (Kirschbaum 1986). These differences are due to the way the leaves receive irradiance. Bifacial leaves, which are usually planophile (perpendicular to the stem), receive most light from the adaxial surface while isobilateral leaves receive light from both sides. The distribution of Rubisco and electron transport components within these two types of leaves are different. Besides these biochemical differences, Lloyd et al. (1992) and Syvertsen et al. (1995) found that the mesophyll of leaves exposed to different light intensities also changes, and so it might be that these two types of leaves differ anatomically as well.

The optimal distribution of the photosynthetic machinery (Rubisco activity and electron transport) would follow the gradient of irradiance in a theoretical bifacial 
leaf, receiving irradiance from one direction, as shown mathematically by Farquhar (1989), while in isobilateral leaves a bimodal distribution would be expected as light comes from both sides of the leaves (Kirschbaum 1986). Any functional isobilaterality will affect the interpretation of the gas exchange data as gas exchange measurement normally was done with irradiance given to the upper side of the leaf (adaxial surface) only.

Light gradients in the leaves were not included in the model of Farquhar et al. (1980), although a steep light gradient does exist within leaves (Terashima \& Saeki 1983; Vogelmann \& Björn 1984). For a bifacial leaf, even without the consideration of the light gradient within the leaves, the model shows good agreement with measured data (Harley et al. 1985; June 2002), presumably for the reason noted above. However, for isobilateral leaves the model may not give a good representation of the relationship between capacities (e.g., Rubisco and electron transport) and actual photosynthesis rate as function of irradiance, in a conventional gas exchange system.

\section{MATERIALS AND METHODS}

\section{Plant Materials}

Indeterminate soybean (Glycine max [L.] Merr.) were grown in 12 liter plastic pots containing sand and vermiculate mixture $(1: 1, \mathrm{v} / \mathrm{v})$. Plants were exposed to a controlled environment in a growth chamber where relative humidity was kept constant at $60 / 70 \%$ day/night and three temperatures: $20 / 15,25 / 20$ and 32/27 day/night ${ }^{\circ} \mathrm{C}$ with $\left[\mathrm{CO}_{2}\right]$ of $350 \mu \mathrm{mol} \mathrm{mol}{ }^{-1}$.

\section{Models of leaf photosynthesis}

Leaf photosynthesis can be described by the equations developed by Farquhar et al. (1980) and Farquhar \& von Caemmerer (1982). The rate of photosynthesis is controlled by Rubisco (RuBP carboxylase-oxygenase), the rate of regeneration of $\mathrm{RuBP}$, and the relative partial pressures of $\mathrm{CO}_{2}\left(c_{\mathrm{i}}\right)$ and $\mathrm{O}_{2}$ at the site of $\mathrm{CO}_{2}$ fixation. Under a given set of environmental conditions, the net $\mathrm{CO}_{2}$ assimilation rate, $A$, is taken as being either the Rubisco-limited rate, $A_{v}$, or the predicted RuBPregeneration limited rate of photosynthesis, $A_{\mathrm{j}}$, whichever is the lower at a particular $c_{\mathrm{i}}$. (This holds for $\mathrm{ci}>\Gamma^{*}$, the $\mathrm{CO}_{2}$ compensation partial pressure in the absence of dark respiration.) $A$ has units of $\mu \mathrm{mol} \mathrm{m} \mathrm{m}^{-2} \mathrm{~s}^{-1}$.

$$
A_{j}=\frac{J}{4}\left(\frac{c_{i}-\Gamma *}{c_{i}+2 \Gamma *}\right)-R_{d}
$$


$A_{v}=V_{c \max }\left(\frac{c_{i}-\Gamma^{*}}{K_{c}\left(1+O / K_{o}\right)+c_{i}}\right)-R_{d}$

$A=\min \left(A_{\mathrm{j}}, A_{\mathrm{v}}\right)$

where $c_{\mathrm{i}}=$ partial pressure of $\mathrm{CO}_{2}$ in the leaf $(\mu \mathrm{bar}) ; \Gamma^{*}=\mathrm{CO}_{2}$ compensation partial pressure in the absence of dark respiration $(\mu \mathrm{bar}) ; R_{\mathrm{d}}=$ dark respiration by the leaf which continues in the light $\left(\mu \mathrm{mol} \mathrm{m} \mathrm{s}^{-2}\right) ; O=$ ambient partial pressure of oxygen (mbar); $K_{\mathrm{c}}$ and $K_{\mathrm{o}}$ are Michaelis-Menten constants for carboxylation and oxygenation by Rubisco ( $\mu$ bar and mbar, respectively); $V_{\text {cmax }}$ is the maximum rate of Rubisco activity in the leaf $\left(\mu \mathrm{mol} \mathrm{m} \mathrm{m}^{-2} \mathrm{~s}^{-1}\right)$; and $J$ is the actual electron transport rate $\left(\mu \mathrm{mol} \mathrm{m} \mathrm{m}^{-2} \mathrm{~s}^{-1}\right)$. The temperature dependence of $K_{\mathrm{c}}$ and $K_{\mathrm{o}}$ follows the Arrhenius function:

$$
\begin{aligned}
& K_{c}=K_{c, 25} \exp \left[\frac{E_{c}}{298.2 R}\left(1-\frac{298.2}{(T+273)}\right)\right] \\
& K_{o}=K_{o, 25} \exp \left[\frac{E_{o}}{298.2 R}\left(1-\frac{298.2}{(T+273)}\right)\right]
\end{aligned}
$$

where $R$ is the universal gas constant, $8.3144 \mathrm{~J} \mathrm{~mol}^{-1} \mathrm{~K}^{-1}$, and $T$ is temperature in ${ }^{\circ} \mathrm{C}$. $E_{\mathrm{c}}$ and $E_{\mathrm{o}}$ are the apparent activation energies and the 25 subscript refers to the value at $25^{\circ} \mathrm{C}$.

The temperature effect on the $\mathrm{CO}_{2}$ compensation point of photosynthesis in the absence of mitochondrial respiration follows the equation of von Caemmerer et al. (1994):

$$
\Gamma^{*}=36.9+1.88(T-25)+0.036(T-25)^{2}
$$

The parameters $K_{\mathrm{c}}$ and $K_{\mathrm{o}}$ indicate the intrinsic kinetic properties of Rubisco. They are relatively constant, varying only with temperature for all $\mathrm{C}_{3}$ species (Berry \& Björkman 1980; Jordan \& Ogren 1984), and hence in this analysis the values presented by Badger \& Collatz (1977) and von Caemmerer et al. (1994) were used. The values for $K_{\mathrm{c}}, K_{\mathrm{o}}$ and $\Gamma^{*}(\mathrm{~Pa})$ at $25^{\circ} \mathrm{C}$ are $40.4,24800,3.69$ and the activation energies $\left(\mathrm{J} \mathrm{mol}^{-1}\right)$ for $K_{\mathrm{c}}$ and $K_{\mathrm{o}}$ are 59400, 36000, respectively, assuming wall conductance $\mathrm{g}_{\mathrm{w}}=\infty$ (von Caemmerer et al. 1994; Badger \& Collatz 1977). The rate of electron transport, J, follows the equation by Farquhar \& Wong (1984): 


$$
J=\frac{I a_{2}+J_{\max }-\sqrt{\left(I a_{2}+J_{\max }\right)^{2}-4 \Theta I a_{2} J_{\max }}}{2 \Theta}
$$

where $J_{\max }$ is the maximum light-saturated rate of electron transport of the leaf $\left(\mu \mathrm{mol} \mathrm{m} \mathrm{m}^{-2} \mathrm{~s}^{-1}\right), \Theta$ is the curvature factor of the light response curve that varies from 0 (rectangular hyperbola) to 1 (two straight lines quasi Blackman), $a_{2}$ is the quantum yield (in terms of incident PAR) of electron transport at low light and $I$ is the light intensity $\left(\mu \mathrm{mol} \mathrm{m} \mathrm{m}^{-2}\right)$ incident on the leaf.

\section{RESULTS AND DISCUSSIONS}

\section{Example of light response curves}

From the measurement of the light response curves, where the incident light ranged from 0 to $1650 \mu \mathrm{mol} \mathrm{m}^{-2} \mathrm{~s}^{-1}, R_{\mathrm{d}}$ was determined by extrapolation of a linear regression at the lower end of the response curve (at $I=0-150 \mu \mathrm{mol} \mathrm{m}^{-2} \mathrm{~s}^{-1}$ ). Using this interpolated $R_{\mathrm{d}}$ along with $\Gamma^{*}$ corrected for each temperature using Equation (6), $J$ was calculated from Eq. (1) and then $J_{\max }, \theta$ and $a_{2}$ were estimated by fitting the $J$ irradiance curve with Equation (7). Figure 1 shows example of the light response curves of the electron transport rate for plants grown at $\left[\mathrm{CO}_{2}\right]$ of $350 \mu \mathrm{mol} \mathrm{mol}^{-1}$ and air temperatures of $32 / 27^{\circ} \mathrm{C}$ and $20 / 15^{\circ} \mathrm{C}$ (day/night) and measured at the gas exchange at three different temperatures. The electron transport rate was calculated using Eq. (1).

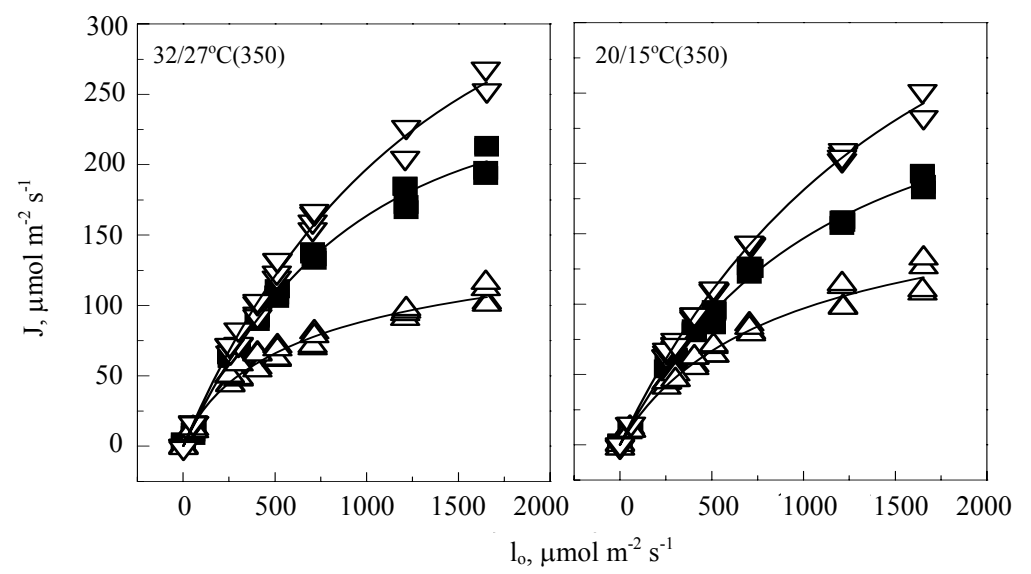

Figure 1. Light response curves of the electron transport rate measured at three temperatures $\left(\Delta: 15^{\circ} \mathrm{C}\right.$; : $25^{\circ} \mathrm{C}$ and $\nabla: 35^{\circ} \mathrm{C}$ ). Plants were grown under different conditions as indicated in the graph and measured at $\left[\mathrm{CO}_{2}\right]$ of $700 \mu \mathrm{mol} \mathrm{mol}{ }^{-1}$. 
The light gradients inside soybean leaves and their effect on the curvature factor - Tania June

\section{The negative curvature factor $(\Theta)$ and its effect on the estimation of $J_{\max }$}

When these soybean plants were grown in the growth chambers, about $11 \%$ of the incident light was reflected from the metal base of the chamber onto the lower surface of the leaf, resulting in a changed distribution of light and hence, presumably, of photosynthetic capacity inside the leaf. In other words it became partially isobilateral. When the light response curve of this leaf was measured by gas exchange, with light reaching only the upper surface of the leaf, the upper and lower surfaces of the leaf will have saturated at different "times", i.e. at different irradiances on the adaxial surface. This means that chloroplasts near the abaxial surface continue to increase in irradiance at levels where the adaxial chloroplasts are light saturated. This continuous response at high irradiance will result in a very low fitted curvature factor, $\Theta$, as shown in the following parts.

The value of rate of bending, $\Theta$, tended to be 1 (Leverenz 1987; Oya \& Laisk 1976) as the distribution of light given during the gas exchange measurement was made more nearly proportional to the distribution of the photosynthetic capacity (developed during growth). The soybean data showed that when gas exchange measurement with the light source aimed at the top part of the leaf was done, the value of $\Theta$ was -1.86 at $15^{\circ} \mathrm{C}, 0.6$ at $35^{\circ} \mathrm{C}$ and then decreased to -0.39 at $40^{\circ} \mathrm{C}$ (June 2002). I hypothesise that the very low value of $\Theta$ was due to the proportion of light given to each surface of the leaf during measurement not being similar to what the leaf received during growth. If some levels of light reached the lower leaf surface during gas exchange measurements, then this low value of $\Theta$ should increase as was suggested by Oya \& Laisk (1976), Leverenz (1987) and Farquhar (1989).

\section{Fitted Parameters $\left(\mathrm{J}_{\max }, \Theta, \mathbf{a}_{2}\right)$}

The fitted parameters as functions of the growth and measurement temperatures are listed in Table 1 ( $a_{2}$ and $\Theta$ fitted freely) and Table 2 ( $a_{2}$ constrained) using Eq. (7) with $J$ from Eq. (1) and $g_{\mathrm{w}}=\infty$, and varying the fitting procedure as described below. The fitted parameters $a_{2}, J_{\max }$ and $\Theta$ in Table 1 resulted from the fitting procedure where all the parameters vary freely. The estimation of $\Theta$ (curvature factor) was very low, reaching -4.85 for plants grown at $32 / 27^{\circ} \mathrm{C}$ when measured at $15^{\circ} \mathrm{C}$. A negative value of $\Theta$ has never been observed before, as the normal values range from 0 to 1 (Farquhar \& Wong 1984). The estimation of $J_{\max }$ becomes unrealistically high if $\Theta$ is very low. In this case, it reached $407 \mu \mathrm{mol}$ $\mathrm{m}^{-2} \mathrm{~s}^{-1}$ at $15^{\circ} \mathrm{C}$, which is $85 \%$ higher than the $J_{\max }$ value at $25^{\circ} \mathrm{C}$ and $17 \%$ higher than $J_{\max }$ at $35^{\circ} \mathrm{C}$; this is implausible as $J_{\max }$ is expected to increase with temperature from 15 to $35^{\circ} \mathrm{C}$, as with other growth conditions in Table 1 . 
BIOTROPIA NO. 25, 2005

Table 1. List of model parameters with \pm s.e, for each measurement at 3-leaf temperatures and a $\mathrm{CO}_{2}$ concentration of $700 \mu \mathrm{mol} \mathrm{mol}{ }^{-1}$. Fitting of the light response curve was done using Eq. (7) by letting all the parameters fit freely and assuming $g_{w}=\infty$.

\begin{tabular}{|c|c|c|c|c|c|}
\hline \multirow{2}{*}{$\begin{array}{c}\text { Growth } \\
\text { condition } \\
\text { day } T /\left[\mathrm{CO}_{2}\right]\end{array}$} & \multirow{2}{*}{$\begin{array}{c}\text { Leaf } \\
\text { Temperature } \\
\left.{ }^{\circ} \mathrm{C}\right)\end{array}$} & \multicolumn{4}{|c|}{$\begin{array}{l}\text { Parameters of light response curve, measured at } 700 \mu \mathrm{mol} \mathrm{mol}^{-1} \\
\qquad\left[\mathrm{CO}_{2}\right]\end{array}$} \\
\hline & & $\boldsymbol{R}_{\mathrm{d}}$ & $a_{2}$ & $J_{\max }$ & $\Theta$ \\
\hline \multirow[t]{3}{*}{$20 / 350$} & 15 & $0.65 \pm 0.25$ & $0.25 \pm 0.01$ & $268 \pm 101$ & $-1.70 \pm 1.30$ \\
\hline & 25 & $1.15 \pm 0.05$ & $0.24 \pm 0.01$ & $291 \pm 28$ & $0.35 \pm 0.20$ \\
\hline & 35 & $2.60 \pm 0.20$ & $0.28 \pm 0.01$ & $614 \pm 258$ & $-0.24 \pm 0.76$ \\
\hline \multirow[t]{3}{*}{$20 / 700$} & 15 & $0.35 \pm 0.25$ & $0.27 \pm 0.07$ & $185 \pm 22$ & $-0.40 \pm 0.51$ \\
\hline & 25 & $0.55 \pm 0.21$ & $0.25 \pm 0.01$ & $283 \pm 50$ & $0.78 \pm 0.10$ \\
\hline & 35 & $2.15 \pm 0.15$ & $0.27 \pm 0.02$ & $303 \pm 17$ & $0.90 \pm 0.02$ \\
\hline \multirow[t]{3}{*}{$25 / 350$} & 15 & $0.12 \pm 0.12$ & $0.15 \pm 0.04$ & $200 \pm 115$ & $-1.00 \pm 1.87$ \\
\hline & 25 & $1.01 \pm 0.44$ & $0.22 \pm 0.01$ & $212 \pm 43$ & $0.70 \pm 0.05$ \\
\hline & 35 & $1.74 \pm 0.06$ & $0.27 \pm 0.02$ & $284 \pm 42$ & $0.84 \pm 0.01$ \\
\hline \multirow[t]{3}{*}{$32 / 350$} & 15 & $0.00 \pm 0.00$ & $0.34 \pm 0.06$ & $162 \pm 4$ & $-1.20 \pm 0.20$ \\
\hline & 25 & $0.80 \pm 0.20$ & $0.28 \pm 0.02$ & $277 \pm 21$ & $0.56 \pm 0.04$ \\
\hline & 35 & $2.25 \pm 0.15$ & $0.31 \pm 0.02$ & $449 \pm 0.2$ & $0.31 \pm 0.05$ \\
\hline \multirow[t]{3}{*}{$32 / 700$} & 15 & $0.00 \pm 0.00$ & $0.21 \pm 0.00$ & $407 \pm 181$ & $-4.85 \pm 3.55$ \\
\hline & 25 & $1.00 \pm 0.04$ & $0.25 \pm 0.04$ & $220 \pm 21$ & $0.00 \pm 0.49$ \\
\hline & 35 & $2.15 \pm 0.07$ & $0.24 \pm 0.01$ & $347 \pm 31$ & $0.76 \pm 0.10$ \\
\hline
\end{tabular}

Leverenz (1988) discussed the strong correlation between the estimate of $a_{2}$ and that of $\Theta$, which in some cases results in an unrealistically low estimate of $a_{2}$ and an unusually high estimate of $\Theta$. Based on Table 1, there is no definite trend in $a_{2}$ with increasing temperature, although there is a tendency for the value to be lower at 15 ${ }^{\circ} \mathrm{C}$ than at $35^{\circ} \mathrm{C}$ as shown by $60 \%$ of the data.

The parameter $a_{2}$ (quantum yield of electron transport) has a theoretical maximum of 0.5 in red light (due to two photosystems) and 0.375 in white light. In practice, these values are usually lower (for example, by $15 \%$, Kirschbaum \& Farquhar 1987).

Several studies have shown that the quantum yield of $\mathrm{CO}_{2}$ assimilation decreases as temperature increases between 15 and $35^{\circ} \mathrm{C}$ (when measured at ambient $\left.\left[\mathrm{CO}_{2}\right]\right)$. For example, Ehleringer \& Björkman (1977), with Encelia california; Ku \& Edwards (1978) with Triticum aestivum; Ehleringer \& Pearcy (1983) with Avena sativa; Osborne \& Garrett (1983) with Lolium perenne; Leverenz \& Oquist (1987) 
with Pinus sylvestris. These yields are complicated by the increasing proportion of light energy used for photorespiration at higher temperatures. There are few temperature studies that have eliminated the effects of RuBP oxygenation by either working at low $\left[\mathrm{O}_{2}\right]$, high $\left[\mathrm{CO}_{2}\right]$, or by correcting the measurements using light given both from the top and bottom surfaces of the leaves.

However, Harley et al. (1985) working with soybean found that $a_{2}$ increased from 0.16 at $15^{\circ} \mathrm{C}, 0.21$ at $20^{\circ} \mathrm{C}, 0.27$ at $25^{\circ} \mathrm{C}, 0.26$ at $30^{\circ} \mathrm{C}, 0.25$ at $35^{\circ} \mathrm{C}$ and down to 0.22 at $40^{\circ} \mathrm{C}$. There may be some difficulties in comparing these values with ours as they used a different equation from Eq. 3.7 that had no independent cuvature term. Wang et al. (1996), working with Scots pine, found that $a_{2}$ increased from 0.18 at $6^{\circ} \mathrm{C}$ to 0.30 at $21^{\circ} \mathrm{C}$ and decreased to 0.23 by $32^{\circ} \mathrm{C}$.

There are no consistent differences in $a_{2}$ observed between the growth treatments in this experiment. Osborne \& Garrett (1983) and Leverenz \& Oquist (1987) showed evidence that low temperature stress and frost hardening may change membrane properties and result in lower $a_{2}$. According to Wilkins et al. (1994), the difference in the values of $a_{2}$ between growth treatments could reflect changes in the structure of the needle tissue, the chlorophyll content and the structure of the thylakoid membrane.

With all parameters fitted freely in Table 1, there was only a slight tendency for $a_{2}$ to increase with short-term temperature variation from $0.24 \pm 0.06$ at $15^{\circ} \mathrm{C}$, to $0.25 \pm 0.02$ at $20^{\circ} \mathrm{C}$ and $0.27 \pm 0.02$ at $35^{\circ} \mathrm{C}$. The mean value is $0.26 \pm 0.04$. This value is slightly higher than the mean value (0.23) across all temperatures found by Harley et al. (1985) for soybean, and slightly less than that, 0.28 , found by Kirschbaum \& Farquhar (1987) in Eucalyptus pauciflora, at $25^{\circ} \mathrm{C}$, when allowance is made for an absorptance of 0.9. It is identical to the value found by Ehleringer \& Björkman (1977) for quantum yield in white light as a mean of seven species. In $2 \%$ $\left[\mathrm{O}_{2}\right]$ they obtained a quantum yield of $\mathrm{CO}_{2}$ assimilation 0.0733 . Multiplying by $4 \overline{\mathrm{e}} / \mathrm{CO}_{2}$ and by an assumed absorptance of 0.9 yields $a_{2}=0.26$. Other data on quantum yield in white light and low $\left[\mathrm{O}_{2}\right]$ of $\mathrm{CO}_{2}$ assimilation of sets of $\mathrm{C}_{3}$ species summarised by Evans (1987) are 0.296 and 0.324 [with 0.328 and 0.388 in two individual studies].

To reduce the effect of "noise" in $a_{2}$ on the estimates of $\Theta$, a second set of fitting procedures was used holding $a_{2}$ constant at 0.26 . The resulting fitted parameters $\Theta$ and $J_{\max }$ are shown in Table 2. With $a_{2}$ held constant, the effect of temperature on $\Theta$ becomes more consistent. $\Theta$ increases with temperature in all cases and so does the estimate of $J_{\max }$, except for the data coming from plants grown at $32 / 27^{\circ} \mathrm{C}, 700 \mu \mathrm{mol} \mathrm{mol}^{-1}\left[\mathrm{CO}_{2}\right]$, where $J_{\max }$ is still very high at $15^{\circ} \mathrm{C}$ associated with a probably due to the very low fitted value of $\Theta$.

In most cases the value of $\Theta$ was still very low, and negative in almost half of the cases. A total of $67 \%$ of the data set shows a $\Theta$ value lower than the commonly accepted value of 0.7 (Farquhar \& Wong 1984, Evans \& Terashima 1988, Evans \& Farquhar 1991). 
BIOTROPIA NO. 25, 2005

Table 2. List of model parameters with \pm standard error, for each measurement at 3-leaf temperatures and a $\mathrm{CO}_{2}$ concentration of $700 \mu \mathrm{mol} \mathrm{mol}^{-1}$. Fitting of the light response curve was done using $\mathrm{a}_{2}=0.26$ and assuming $\mathrm{g}_{\mathrm{w}}=\infty$.

\begin{tabular}{|c|c|c|c|}
\hline \multirow{2}{*}{$\begin{array}{c}\text { Growth } \\
\text { condition, } \\
\text { day } T /\left[\mathrm{CO}_{2}\right]\end{array}$} & \multirow[t]{2}{*}{ Leaf Temperature $\left({ }^{\circ} \mathrm{C}\right)$} & \multicolumn{2}{|c|}{$\begin{array}{l}\text { Parameters of the light response curve, } \\
\text { measured at } 700 \mu \mathrm{mol} \mathrm{mol}^{-1}\left[\mathrm{CO}_{2}\right]\end{array}$} \\
\hline & & $J_{\max }$ & $\Theta$ \\
\hline \multirow[t]{3}{*}{$20 / 350$} & 15 & $277 \pm 98$ & $-2.01 \pm 1.14$ \\
\hline & 25 & $331 \pm 11$ & $0.002 \pm 0.003$ \\
\hline & 35 & $444 \pm 115$ & $0.39 \pm 0.26$ \\
\hline \multirow[t]{3}{*}{$20 / 700$} & 15 & $190 \pm 18$ & $-0.56 \pm 0.77$ \\
\hline & 25 & $311 \pm 48$ & $0.70 \pm 0.10$ \\
\hline & 35 & $300 \pm 35$ & $0.92 \pm 0.03$ \\
\hline \multirow[t]{3}{*}{$25 / 350$} & 15 & $197 \pm 67$ & $-5.75 \pm 3.39$ \\
\hline & 25 & $264 \pm 58$ & $0.16 \pm 0.02$ \\
\hline & 35 & $274 \pm 18$ & $0.84 \pm 0.10$ \\
\hline \multirow[t]{3}{*}{$32 / 350$} & 15 & $134 \pm 18$ & $-0.05 \pm 0.54$ \\
\hline & 25 & $267 \pm 35$ & $0.65 \pm 0.08$ \\
\hline & 35 & $326 \pm 14$ & $0.81 \pm 0.08$ \\
\hline \multirow[t]{3}{*}{$32 / 700$} & 15 & $490 \pm 154$ & $-9.10 \pm 4.20$ \\
\hline & 25 & $236 \pm 25$ & $-0.16 \pm 0.30$ \\
\hline & 35 & $585 \pm 14$ & $-0.04 \pm 0.07$ \\
\hline
\end{tabular}

However, apart from my data there is supporting evidence that the best fit of $\Theta$ can be lower than 0.7 , as shown by Wang et al. (1996) who found that $\Theta$ ranges from 0.32 to 0.66 for Scots pine grown and measured at different conditions. However, in contrast to the results obtained in this worl, they found that $\Theta$ decreased with increasing temperature across the whole range examined.

Smaller values of $\Theta$ are observed when the light response curves are measured using light given solely from the abaxial rather than the normal adaxial surface (Oya \& Laisk 1976; Terashima \& Saeki 1985; Terashima 1986). Leverenz (1988) found that $\Theta$ values increased as the leaf acclimated to the light environment inside an integrating sphere (measurement was done at ambient $\mathrm{CO}_{2}$ concentration).

The values of $J_{\max }$ were obtained from fitting the light response measurements at temperatures of 15,25 and $35^{\circ} \mathrm{C}$ and for plants with different growth conditions using Eqs. (1), (2), (7) and (8). 


\section{What is the meaning of a negative value of $\Theta$ ? What does the fitted curve look like with a negative $\Theta$ ?}

To answer these questions, potential electron transport rate, $J$, was calculated for values of $\Theta$ ranging from 1 to -9 , with $I_{2}$ ranging from 0 to $4000 \mu \mathrm{mol} \mathrm{m}^{-2} \mathrm{~s}^{-1}$ for each $\Theta$, as shown in Figure 2. It can be seen that for curves with a negative value of $\Theta$, the electron transport rate, $J$, does not saturate (i.e. level off) even at $I_{2}=4000$ $\mu \mathrm{mol} \mathrm{m} \mathrm{m}^{-2}$.

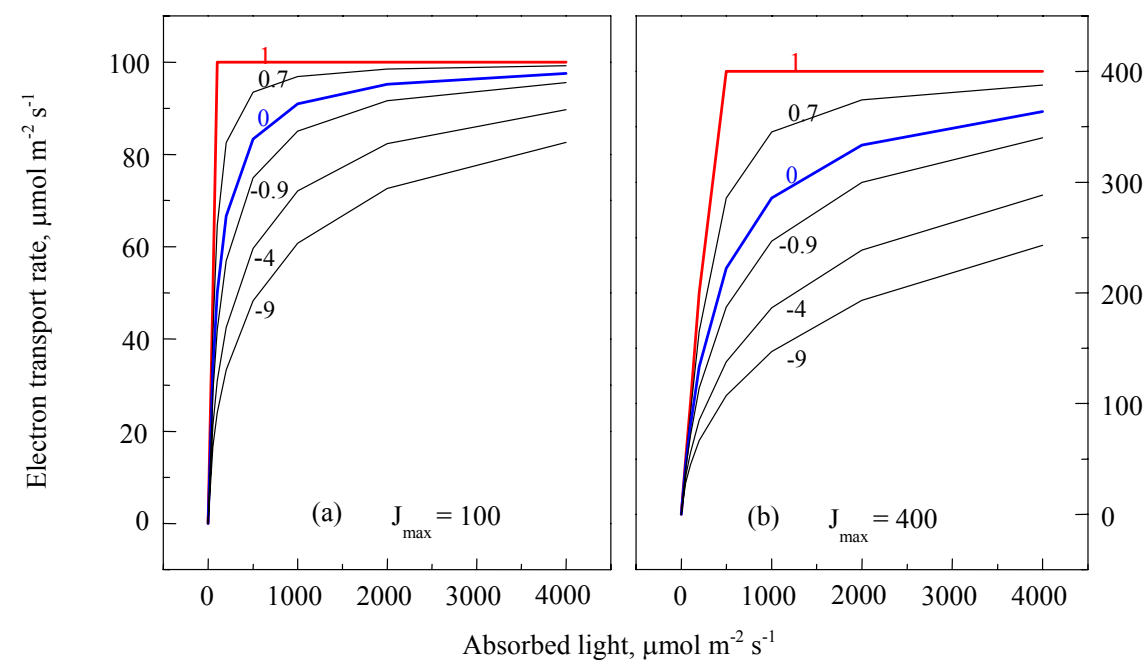

Figure 2. The effect of changing the curvature factor $(\Theta)$ on the response curve of electron transport at (a) low and (b) high $J_{\max }$. Curves were generated using Eq. (7).

The value of $I_{2}$ where $J$ starts to saturate will determine the fitted value of $\Theta$, as shown in Figure 3. As saturation starts earlier (at lower $I_{2}$ ), $\Theta$ will become higher. For example, when saturation started at $I_{2}=200 \mu \mathrm{mol} \mathrm{m} \mathrm{m}^{-2} \mathrm{~s}^{-1}$, the estimated $\Theta$ was 0.999 , while when saturation started at $I_{2}=1000 \mu \mathrm{mol} \mathrm{m} \mathrm{m}^{-2} \mathrm{~s}^{-1}, \Theta$ was 0.77 .

It can be argued that the light response curves which were measured here at $I$ up to $1650 \mu \mathrm{mol} \mathrm{m} \mathrm{m}^{-2} \mathrm{~s}^{-1}$ in soybean leaves did not reach saturation, in particular at $15^{\circ} \mathrm{C}$, and hence the estimation of $\Theta$ was too low. As an example, when the $J$ value from the $\Theta=0$ curve at $I_{2}=4000 \mu \mathrm{mol} \mathrm{m} \mathrm{m}^{-2} \mathrm{~s}^{-1}$ in Fig. 2 (b) was increased by only $4.6 \%$ and then refitted using Eq. (7) to find $\Theta$ again, the value of $\Theta$ dropped from 0 to -0.36 (see top two curves in Fig. 3).

One interpretation of the above results is that as light becomes more available (higher I), more light will be distributed to the bottom part of the leaf where photosynthetic capacity is probably increasing. This may be due to the leaf receiving 
some light from the lower metal base of the growth chamber and adjusting its photosynthetic capacity accordingly. This will increase $J$ and, therefore, decrease the value of $\Theta$. When the value of $\Theta$ becomes too small (negative), significant overestimation of $J_{\max }$ using Eq .(7) will occur.

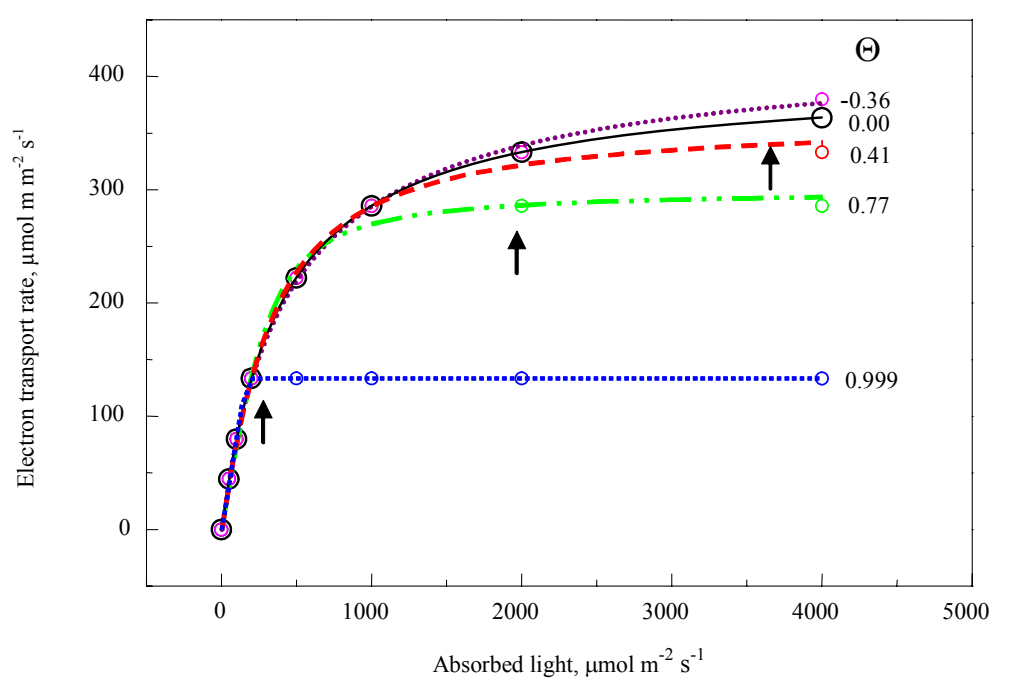

Figure 3. The effect of the starting point of saturation of $J$ on the estimated value of $\Theta$. Data were generated initially with $\Theta=0$ as in Figure 2 (b). Arrows indicate point of saturation.

\section{Theoretical Simulation}

In the following part I will explain the mechanisms of the negative $\Theta$ by means of simulation. In the simulation, the leaf is divided into 10 layers. Division of layers is based on equal amounts of chlorophyll in each layer. The contribution of each layer to the leaf $\mathrm{CO}_{2}$ assimilation rate is determined by the amount of light absorbed and the photosynthetic capacity. The photosynthetic capacity is given by $J_{\max }$. According to Kirschbaum (1986), who applied a modified Kubelka-Munk theory, the pattern of space irradiance within the leaf can be approximated by an exponential curve:

$$
I_{\mathrm{i}}=I_{o} c_{1} \exp \left(-c_{2} i\right)
$$

where $I_{\mathrm{i}}$ is the space irradiance at any layer $i, I_{\mathrm{o}}$ is irradiance incident on the top of the leaf, $c_{1}(>1)$ and $c_{2}$ are parameters specific for each leaf (dimensionless) and $i$ is the layer number where $i$ is $0<i<D$, in units of $1 / D \times$ total absorptance ( $D$ is total number of layers in leaf). Note that the space irradiance in the top layer, $I_{1}$, is 
generally greater than $I_{0}$ because of internal reflections. The space irradiance in the top layer of the leaf $\left(I_{1}\right)$ and in the bottom layer of the leaf $\left(I_{\mathrm{D}}\right)$, can be calculated (Kirschbaum 1986):

$$
\begin{aligned}
& \frac{I_{1}}{I_{o}}=1-r_{o}+\left(R-r_{o}\right) \frac{\left(1+r_{u}\right)}{\left(1-r_{u}\right)} \\
& \frac{I_{D}}{I_{o}}=T \frac{\left(1+r_{l}\right)}{\left(1-r_{l}\right)}
\end{aligned}
$$

where $r_{0}$ is reflection at the air-to-leaf interface, $r_{\mathrm{u}}$ and $r_{1}$ are internal reflectivities at the upper and lower leaf-to-air interfaces, and $\mathrm{R}$ and $\mathrm{T}$ are total reflectance and transmissivity. Values for $r_{u}, r_{o}$ and $r_{1}(0.37,0.037$ and 0.37 respectively) are given by Jenkins \& White (1957), for a refractive index of 1.48 from calculations based on the theory of geometrical optics. Using Equations (9) and (10) for incident irradiance of $1200 \mu \mathrm{mol} \mathrm{m} \mathrm{s}^{-1}, R=0.0741$ and $T=0.0143$ gives $I_{1}=1252 \mu \mathrm{mol} \mathrm{m} \mathrm{m}^{-2} \mathrm{~s}^{-1}$ and $I_{10}$ $=37.32 \mu \mathrm{mol} \mathrm{m}^{-2} \mathrm{~s}^{-1}$ (June, 2002). These values are then inserted into Eq. (8) taking 10 layers $(D=10)$ to give $c_{1}=1.2806$ and $c_{2}=0.372$.

Equation (11) says that the light absorbed by any layer, $I$, will be $a I_{0} \exp \left(-i c_{2}\right) /$ $\Sigma^{\mathrm{D}}{ }_{i=1} \exp \left(-i c_{2}\right)$ where $a$ is absorptance of the leaf given by $1-R-T$. Light effectively absorbed by Photosystem II at each layer, $I_{2}(i)$, would then be given by multiplying the above by $0.5(1-f)$, and the electron transport rate for each layer would become

$J_{i}=\frac{I_{2 i}+J_{\max (i)}-\sqrt{\left(I_{2 i}+J_{\max (i)}\right)^{2}-4 \Theta_{I_{2 i} J_{\max (i)}}}}{2 \Theta}$.

In the case of light incident only on one side of the leaf (upper surface), if

$$
\frac{J_{\max (i)}}{\sum J_{\max (i)}}=\frac{I_{a i}}{\sum I_{a i}}=\frac{\exp \left(-c_{2} i\right)}{\sum \exp \left(-c_{2} i\right)}=k_{1}
$$

where all summations are for $I=1$ to 10 , then

$$
J_{\max (i)}=k_{1} \sum J_{\max (i)}
$$

and therefore $J_{\mathrm{i}} \propto J_{\max (\mathrm{i})} \propto I_{\mathrm{ai}}$ (Farquhar 1989). In this case, the shape $(\Theta)$ of the total $J$ would be the same as the shape for an individual layer, $J_{\mathrm{i}}$. This is true in the ideal case for bifacial leaves as shown in Figure 4. 


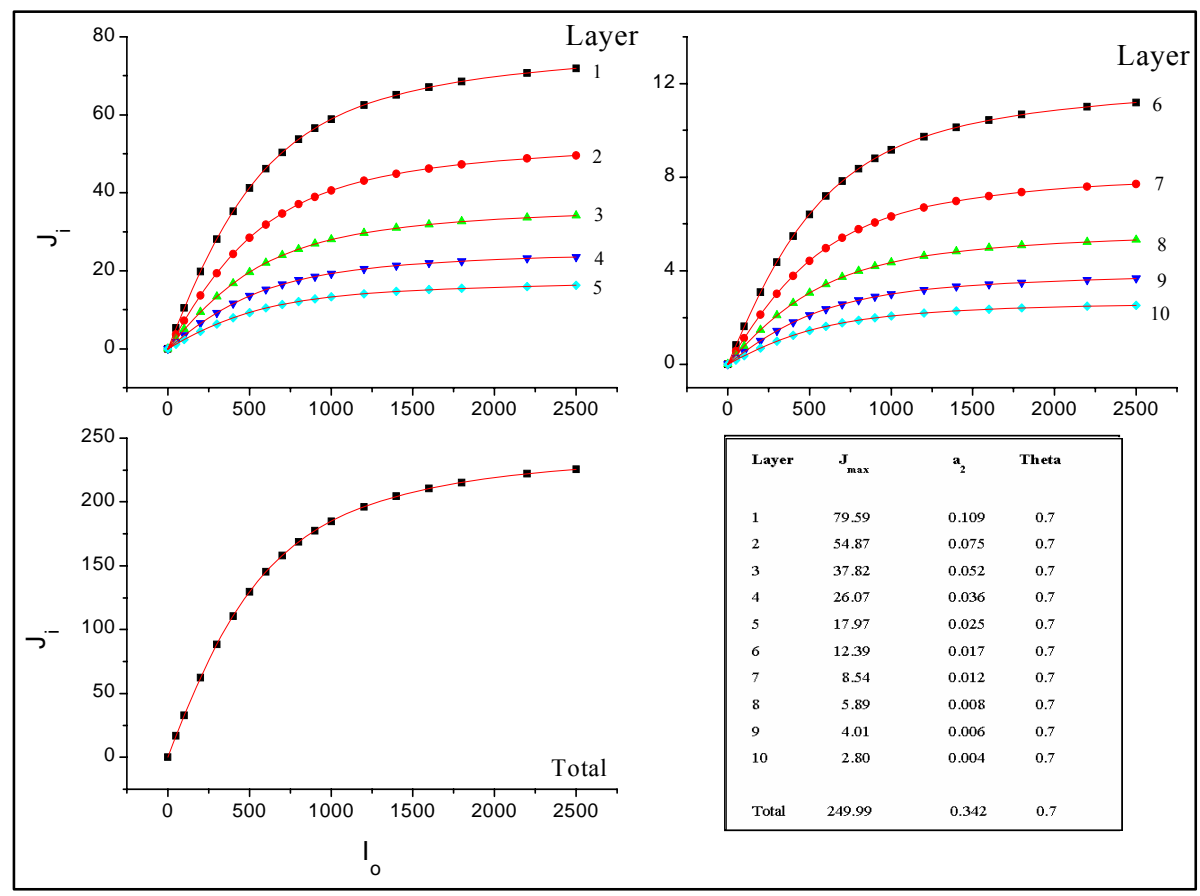

Figure 4. Simulated $J_{\mathrm{i}}$ light response curves of a bifacial leaf. Data were generated with $\mathrm{J}_{\max }=250 \mu \mathrm{mol}$ $\mathrm{m}^{-2} \mathrm{~s}^{-1}, \mathrm{a}_{2}=0.3$ and $\Theta=0.7$. It shows that the shape $(\Theta)$ of the curve for each layer is the same as the shape of the total. The fitting result, represented by the solid line (Eq. (11)), is shown in the inset table.

For a completely isobilateral leaf with, over a period of time such as a day, light reaching the leaf from both sides equally, the time-average of light in each layer would be as shown in Figure 5. 

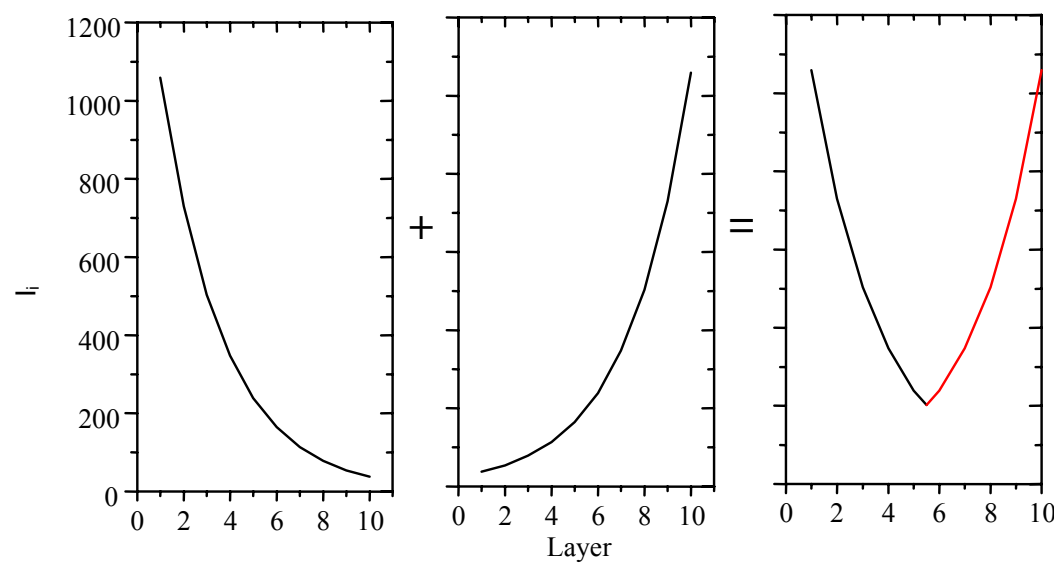

Figure 5. Theoretical light gradient inside an isobilateral leaf (right plot), which is the average of the light gradient from the upper surface (left plot) and the light gradient from the lower surface (middle plot).

The average light in these leaves determines the distribution of $J_{\max (i)}$, where

$$
\begin{aligned}
& \frac{J_{\max (i)}}{\sum J_{\max (i)}}=0.5\left(\frac{\exp \left(-c_{2} i\right)}{\sum \exp \left(-c_{2} i\right)}+\frac{\exp \left(-c_{2}(11-i)\right)}{\sum \exp \left(-c_{2}(11-i)\right)}\right) \\
& =0.5\left(\frac{\exp \left(-c_{2} i\right)+\exp \left(-c_{2}(11-i)\right)}{\sum \exp \left(-c_{2} i\right)}\right) .
\end{aligned}
$$

In the case of soybean leaves, where they are not completely isobilateral (50\% light absorbed from the upper surface and $50 \%$ from the lower surface), Eq. (14) should be modified as follows:

$$
\frac{J_{\max (i)}}{\sum J_{\max (i)}}=\left(\frac{a \exp \left(-c_{2} i\right)+b \exp \left(-c_{2}(11-i)\right)}{\sum \exp \left(-c_{2} i\right)}\right)
$$

where $a$ is the proportion of light reaching the upper surface and $b(=1-a)$ is the proportion of light reaching the lower surface of the leaves. The light absorbed effectively by the Photosystem II at each layer would again be 0.5 (1-f) times the total light absorbed in the layer and $J_{\mathrm{i}}$ would still follow Eq. (11). 
For a leaf which has already adjusted its photosynthetic capacities $\left(J_{\max }\right)$ to its light growing condition (as given by the values of $a$ and $b$ in Eq. (15)), the light response curve of each layer will have a different shape compared to the total when light comes from only one side. The curvature factor, $\Theta$, decreases as the proportion of $J_{\max }$ distributed to the lower part of the leaf, $b$, increases. This happens because the $\left[b \exp \left(-c_{2}(11-i)\right)\right]$ term in Eq. (11) gets bigger and results in increasing that part of the curve at high $I_{0}$, and hence $\Theta$ becomes smaller.

Table 3 shows the simulation results for a theoretical leaf which has a distribution of its photosynthetic capacity as shown by the values of $a$ and $b$ but which is given light reaching only the upper surface. As the proportion of light on the top surface of the leaf during growth $(a)$ deviates more from the measurement condition $(a=1)$, the curvature factor becomes smaller. This is consistent with the hypothesis that a low value of $\Theta$ indicates a mis-match of light distribution during measurement with that experienced during growth.

Table 3. Fitted parameters of simulated data generated with $J_{\max }=50$ and $250 \mu \mathrm{mol} \mathrm{m}^{-2} \mathrm{~s}^{-1}, a_{2}=0.3$ and $\Theta=0.7$, then these parameters were fitted freely using Eq. (11). $\chi^{2}$ shows the goodness of the fitting.

\begin{tabular}{lllllll}
\hline \hline $\boldsymbol{J}_{\max }$ & $\boldsymbol{a}$ & $\boldsymbol{b}$ & $\boldsymbol{J}_{\max }$ & $\boldsymbol{a}_{2}$ & $\Theta$ & $\chi^{2}$ \\
\hline \multirow{250}{*0.9}{} & 1 & 0 & 50.0 & 0.34 & 0.70 & 0.884 \\
& 0.9 & 0.1 & 50.0 & 0.35 & 0.64 & 0.001 \\
& 0.8 & 0.2 & 49.9 & 0.37 & 0.47 & 0.022 \\
& 0.7 & 0.3 & 49.6 & 0.42 & 0.15 & 0.081 \\
& 0.6 & 0.4 & 49.3 & 0.50 & -0.50 & 0.150 \\
& 0.5 & 0.5 & 49.2 & 0.68 & -2.09 & 0.187 \\
& 1 & 0 & 250.0 & 0.34 & 0.70 & 0.788 \\
& 0.9 & 0.1 & 248.4 & 0.35 & 0.66 & 0.027 \\
& 0.8 & 0.2 & 241.6 & 0.35 & 0.59 & 0.176 \\
& 0.7 & 0.3 & 231.8 & 0.36 & 0.51 & 0.432 \\
& 0.6 & 0.4 & 220.8 & 0.37 & 0.39 & 0.778 \\
& 0.5 & 0.5 & 209.3 & 0.38 & 0.20 & 1.184 \\
\hline
\end{tabular}

The light response curve of the photosynthetic system has been hypothesised to be in the form of a quasi-Blackman response, where the curvature factor should approach 1.0 (Leverenz 1987; Leverenz 1988; Oya \& Laisk 1976; Terashima \& Saeki 1985). Therefore, I further simulated the $J$ vs light response curve using a curvature factor equal to 1.0, and the result is shown Table 4 . 
The light gradients inside soybean leaves and their effect on the curvature factor - Tania June

Table 4. Change in the parameters of the light response curve with changing distribution of photosynthetic capacity (as shown by the $a$ value) at $J_{\max }$ total $=50 \mu \mathrm{mol} \mathrm{m}^{-2} \mathrm{~s}^{-1}$ and $250 \mu \mathrm{mol}$ $\mathrm{m}^{-2} \mathrm{~s}^{-1}$. Data were generated with $a_{2}=0.3$ and $\Theta=1.0$ and fitted using Eq. (11). $\chi^{2}$ shows the goodness of the fitting

\begin{tabular}{clllllr}
\hline \hline $\boldsymbol{J}_{\text {max }}$ & $\boldsymbol{a}$ & $\boldsymbol{b}$ & $\boldsymbol{J}_{\max }$ & $\boldsymbol{a}_{2}$ & $\boldsymbol{\Theta}$ & $\chi^{2}$ \\
\hline \multirow{2}{*}{$\mathbf{5 0}$} & 1 & 0 & 50.0 & 0.34 & 1 & 0.015 \\
& 0.9 & 0.1 & 50.1 & 0.36 & 0.98 & 0.034 \\
& 0.8 & 0.2 & 50.2 & 0.39 & 0.90 & 0.392 \\
& 0.7 & 0.3 & 50.4 & 0.46 & 0.70 & 1.446 \\
& 0.6 & 0.4 & 51.1 & 0.65 & -0.003 & 1.958 \\
& 0.5 & 0.5 & 52.7 & 1.74 & -4.89 & 1.421 \\
& 1 & 0 & 250.0 & 0.34 & 1 & 5.857 \\
& 0.9 & 0.1 & 245.9 & 0.35 & 0.99 & 17.009 \\
& 0.8 & 0.2 & 236.3 & 0.36 & 0.98 & 20.620 \\
& 0.7 & 0.3 & 225.4 & 0.38 & 0.94 & 24.577 \\
& 0.6 & 0.4 & 214.8 & 0.40 & 0.88 & 26.370 \\
\hline
\end{tabular}

Table 4 shows that at low $J_{\max }$ the biggest change in the light parameters as the proportion of light coming from the upper and the lower surfaces changes are in $\Theta$ and $a_{2}$, not in $J_{\max } . J_{\max }$ increases by $5.4 \%$ (at low $J_{\max }$ ) when light coming from the lower surface increases from 0 to $50 \%$. When $J_{\max }$ is high, both $\Theta$ and $J_{\max }$ change as the light from the lower surface increases. $J_{\max }$ decreases by $18 \%$ (at high $J_{\max }$ ) when light from the lower surface increases by $50 \%$. A most interesting feature is that the reduction in the apparent value of $\Theta$ is greatest at low $J_{\max }$, and this may explain why $\Theta$ was so low at $15^{\circ} \mathrm{C}$ in data shown in Table 1 .

\section{Methodology to Validate the hypothesis}

In order to test the theory discussed above, another set of soybean plants were grown in a growth chamber at $25^{\circ} \mathrm{C}$ and $\left[\mathrm{CO}_{2}\right]$ of $350 \mu \mathrm{molmol}^{-1}$. The leaves grew with either a black or a reflective surface underneath them during their growing period. The black surface only allowed up to $1.6 \%$ of the incident light (which is reflected from the metal base of the growth chamber) to reach the lower surface of the leaf while the reflective one allowed up to $48 \%$. Some plants were left untreated as control plants. The control plants received $10.9 \%$ of the incident light on the lower surface of its leaves. These three treatments enabled different light gradients inside the leaf to be compared. Leaves from each treatment were then measured by gas exchange, with light reaching only the upper surface and with light reaching both the upper and lower surfaces of the leaf. 
Light response curves of the $\mathrm{CO}_{2}$ assimilation rate with total light intensity from around $50 \mu \mathrm{mol} \mathrm{m} \mathrm{s}^{-2} \mathrm{~s}^{-1}$ to around $1500 \mu \mathrm{mol} \mathrm{m} \mathrm{m}^{-2} \mathrm{~s}^{-1}$ were measured with the following conditions:

1. At $25^{\circ} \mathrm{C}$, the light response curve for one leaf from each of the three conditions (black, control and reflective surface) was measured with $100 \%$ of the light incident on the upper surface. Three replications were done on a single leaf for each growth condition. The data obtained from these measurements were then fitted using Eq. (11) to obtain estimations of $J_{\max }$ and $\mathrm{a}_{2}$ for each growth treatment.

2. The same leaves measured as in point 1 were then measured again by giving an optimum percentage of light to the lower surface at $25^{\circ} \mathrm{C}$ (two replications were done for each growth condition). This optimum percentage was obtained by increasing the proportion of light given to the lower surface of the leaf stepwise until a maximum $\mathrm{CO}_{2}$ assimilation rate and a further decrease with increasing proportion of light were observed. The percentage of light given where this maximum assimilation rate occurred was then used to measure the light response curve. The light intensity used to obtain this optimum percentage was $I_{2}=J_{\max }$, where the maximum bending of the $J$ vs light response curve occurred. $J_{\max }$ was estimated using Eq. (11) with the data set from the earlier measurements in point 1 above. As $I_{2}=I_{0} \mathrm{a}_{2}$, the light intensity used was $I_{0}=J_{\max } / \mathrm{a}_{2}$.

3. Light response curves at 15 and $35^{\circ} \mathrm{C}$ were then measured using the optimum proportion of light given to each side of the leaves as obtained in point 2 (at $\left.25^{\circ} \mathrm{C}\right)$.

The results show that the distribution of incident light needed for maximum photosynthesis follows closely the condition the plant experienced in the growth chamber. The leaf grown with the black surface underneath, which received the least light at the lower leaf surface in the growth chamber, needed only $7.6 \pm 3.0 \%$ of the total light on the lower surface during the gas exchange measurement to reach its maximum value of $\mathrm{CO}_{2}$ assimilation rate. The leaf grown with the reflective surface underneath, which had the highest proportion of light received at the lower leaf surface in the growth chamber, needed $40.0 \pm 10.0 \%$ of the light intensity reaching the lower leaf surface during the measurement to reach its maximum value and the control leaves needs $23.0 \pm 2.1 \%$.

Directing an optimal percentage of the incident light to the lower surface of the leaf during a gas exchange measurement not only increases photosynthesis compared to when light is given to the upper leaf surface only, but it also changes the curvature factor $(\Theta)$ of the light response curve (Table 5, Figure 6). When light was given only to the upper surface of the leaf, $\Theta$ of the reflective leaf was lower than $\Theta$ of the black leaf with the control leaf value in the middle. When measurements were conducted with light given optimally to both sides of the leaf, $\Theta$ increased for all leaves and the value did not differ significantly between growth treatments. The magnitude of this change in $\Theta$, from measurement with upper light 
only to measurement with upper and lower light, becomes larger as the differences in light distribution between growth and measurement conditions become smaller. Hence the change in $\Theta$ with incident light distribution is greater for the reflective leaf than for the black leaf.

Table 5. The effect of giving an optimum percentage of light to the lower surface of the leaf during gas exchange measurements on the $J$ vs light response curve parameters (using $C_{\mathrm{i}}$ ) ( \pm s.e). Measurements were conducted at $25^{\circ} \mathrm{C}$ and $700 \mu \mathrm{mol} \mathrm{mol}^{-1}\left[\mathrm{CO}_{2}\right]$, with 2 replicates for each measurement.

\begin{tabular}{lcc}
\hline \hline Parameters & $\Theta$ & $\boldsymbol{a}_{2}$ \\
\hline Black leaf & & \\
Upper light only & $0.86 \pm 0.06$ & $0.3 \pm 0.08$ \\
Lower and upper light & $0.93 \pm 0.01$ & $0.3 \pm 0.04$ \\
\hline Control leaf & $0.73 \pm 0.04$ & $0.3 \pm 0.05$ \\
Upper light only & $0.90 \pm 0.06$ & $0.3 \pm 0.03$ \\
Lower and upper light & & \\
\hline Reflective leaf & $0.56 \pm 0.07$ & $0.3 \pm 0.04$ \\
Upper light only & $0.93 \pm 0.04$ & $0.3 \pm 0.03$ \\
Lower and upper light & & \\
\hline
\end{tabular}

Figure 6 shows one example of the $J$ vs light response curves from gas exchange measurements with light reaching the upper side only and with light given to both surfaces of the leaf, for each leaf treatment (note the change in the curvature factor). 


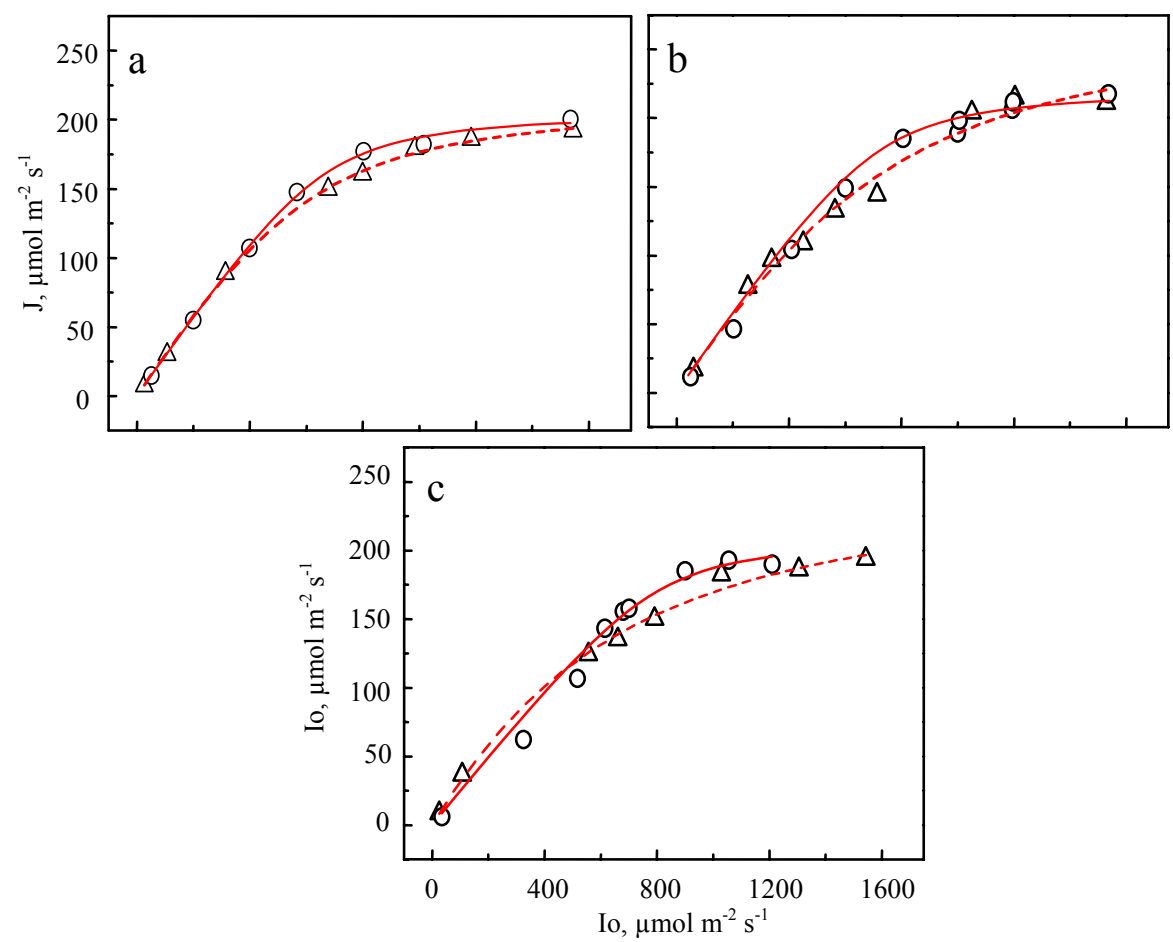

Figure 6. Light response curve of the electron transport rate $(J)$ of (a) black leaf, (b) control leaf and (c) reflective leaf measured with light reaching the upper surface only (triangle, fitted by segmented line) and light reaching both upper and lower surfaces (circle, fitted by solid line). Measurements were done at $25^{\circ} \mathrm{C}$ and $\mathrm{CO}_{2}$ concentration of $700 \mu \mathrm{mol} \mathrm{mol}{ }^{-1}$. Parameters of the response curves are (a) $\Theta=0.84,0.94 ; \mathrm{a} 2=0.3,0.3 ; J_{\max }=215,207$, (b) $\Theta=0.73,0.95$; a2 $=$ $0.3,0.3 ; J_{\max }=276,223$, (c) $\Theta=0.49,0.96 ; \mathrm{a}_{2}=0.3,0.25 ; J_{\max }=259,210$, segmented and solid line, respectively. The optimum percentage of light directed to the lower surface was $10.0 \%, 20.4 \%$ and $50.0 \%$ for black, control and reflective leaf respectively.

\section{CONCLUSIONS}

As found and discussed earlier, $\Theta$ is partly an artefact of the distribution of light intensity in relation to the distribution of photosynthetic capacity, where $\Theta$ will reach 1 if the two distributions match.

During gas exchange measurements, if the proportion of light incident on the upper and lower surfaces of the leaf is similar to the light condition experienced by the leaf during its growing period, then the curvature factor $(\Theta)$ of the light response curve moves closer to 1 , confirming the work by Leverenz (1988), although the 
value of 0.7 has been commonly used in fitting the light response curve as first suggested by Farquhar \& Wong (1984) and Evans \& Terashima (1987) and used by Farquhar \& Evans (1991).

As the proportion of light given to both sides of the leaf deviates further from the leaf's growing condition, the apparent whole leaf curvature factor becomes lower. In the case of a bifacial leaf measured with light only given to the upper surface, the upper and lower parts of the leaf would reach saturation at different light intensities causing the light response curve to bend more slowly and resulting in a lower value of the curvature factor.

This finding has to be taken into consideration when modelling the effect of light on canopy photosynthesis. For example, when using the sun-shade model (de Pury \& Farquhar 1997), the curvature factors for the sun and the shade parts of the canopy would change during the time course of the day. Estimation of $J_{\max }$ depends on the curvature factor value, and hence it is important to have a degree of certainty in this value.

This experiment and associated modelling reveal the effect of a differential distribution of photosynthetic capacity throughout a leaf from the distribution of irradiance. The same concepts apply at the canopy level, which the sun-shade model addresses to an extent.

\section{REFERENCES}

Badger, M.R. and G.J. Collazt. 1977. Studies on the kinetic mechanism of ribulose-1,5 bisphosphate carboxylase reactions, with particular reference to the effect of temperature on kinetic parameters. Carnegie Institute of Washington Yearbook, 76: 355-361.

Berry, J. and O. Bjorkman. 1980. Photosynthetic response and adaption to temperature in higher plants. Annual Review of Plant Physiology, 31: 491-543.

De Pury, D.G.G and G.D, Farquhar 1997. Simple scaling of photosybthesis from leaves to canopies without the errors of big-leaf models. Plant Cell and Environment, 20: 537-557.

Ehleringer, J., and O. Bjorkman. 1977. Quantum Yields for $\mathrm{CO}_{2}$ uptake in $\mathrm{C}_{3}$ and $\mathrm{C}_{4}$ plants:Dependence on temperature, $\mathrm{CO}_{2}$ and $\mathrm{O}_{2}$ concentration. Plant Physiology, 59: 86-90.

Ehleringer, J., and . W. Pearcy. 1983. Variation in quantum yield for $\mathrm{CO}_{2}$ uptake among $\mathrm{C}_{3}$ and $\mathrm{C}_{4}$ plants. Plant Physiology, 73: 555-559.

Evans, J.R. 1987. The dependence of quantum yield on wavelength and growth irradiance. Australian Journal of Plant Physiology, 14: 69-79.

Evans, J.R. and G.D. Farquhar. 1991. Modelind canopy photosynthesis from the biochemistry of the $\mathrm{C}_{3}$ chloroplast. In "Modeling Crop Photosynthesis-from Biochemistry to Canopy". (Eds K.J. Boote and R.S. Loomis.) p. 1-16. (Crop Science Society of America Inc.: Madison).

Evans J. R and I. Terashima. 1987. Effects of nitrogen nutrition on electron transport components and photosynthesis in spinach. Australian Journal of Plant Physiology, 14: 59-68.

Evans J. R and I. Terashima. 1988. Photosynthetic characteristics of spinach leaves grown with different nitrogen treatments. Plants Cell Physiology, 29: 157-165. 
BIOTROPIA NO. 25, 2005

Farquhar, G.D. 1989. Models of integrated photosynthesis in cell and leaves. Philosophical Transaction of the Royal Society of London Series B, 323: 357-368.

Farquhar, G.D., von Caemmerer, S and J.A. Berry. 1980. A biochemical model of photosynthetic $\mathrm{CO}_{2}$ assimilation in leaves of $\mathrm{C}_{3}$ species. Planta, 149: 78-90.

Farquhar, G.D. and S.C. Wong. 1984. An empirical model of stomatal conductance. Australian Journal of Plant Physiology, 11:.191-210.

Farquhar, G. D. and S. von Caemmerer. 1982. Modelling of photosynthetic responses to environmental conditions. Physiological plant ecology. II. Encyclopedia of Plant Physiology, New Series. O. L. Lange, P.S. Nobel, C.B. Osmond and H. Ziegler. Berlin, Springer-Verlag.

Harley, P.C., Weber, J.A. and D.M. Gates. 1985. Interactive effects of light, leaf temperature, $\mathrm{CO}_{2}$ and $\mathrm{O}_{2}$ on photosynthesis in soybean. Planta, 165: 249-263.

Jenkins, F.A. and H.E. White. 1957. Fundamentals of Optics. McGraw Hill (New York, Toronto, London).

Jordan, D.B. and W. L. Ogren. 1984. The $\mathrm{CO}_{2} / \mathrm{O}_{2}$ specificity of ribulose, 1-5-bisphosphate carboxylase/oxygenase. Dependence on ribulosebisphosphate concentration, $\mathrm{Ph}$ and temperature. Planta, 161: 308-313.

June, T. 2002. Environmental Effects on photosynthesis of C3 plants: scaling up from electron transport to the canopy (Study case: Glycine max L. Merr). Environmental Biology, Research School of Biological Sciences. Australian National University. Canberra.

Kirschbaum, M.U.F. 1986. The effect of light, temperature and water stress on photosynthesis in Eucalyptus pauciflora. Ph.D.Thesis, Australian National University, Canberra, pp. 185.

Kirschbaum, M.U.F. and G.D. Farquhar 1987. Investigation of the $\mathrm{CO}_{2}$ dependence of quantum yield and respiration in Eucalyptus pauciflora. Plant Physiology, 83: 1032-1036.

Ku, S.B. and G.E. Edwards. 1978. Oxygen inhibition of photosynthesis. III. Temperature dependence of quantum solubility ratio. Planta, 140: 1-6.

Leverenz, J.W.1987. Chlorophyll content and the light response curve of shade-adapted conifer needles. Physiologia Plantarum, 71: 20-29.

Leverenz, J.W.1988. The effects of illumination sequence, $\mathrm{CO}_{2}$ concentration, temperature and acclimation on the convexity of the photosynthetic light response curve. Physiologia Plantarum, 74: $332-341$.

Leverenz, J.W. and G. Oquist. 1987. Quantum yields of photosynthesis at temperatures between $-2^{\circ} \mathrm{C}$ and $35^{\circ} \mathrm{C}$ in a cold-tolerant $\mathrm{C}_{3}$ plant (Pinus sylvestris) during the course of year. Plant, Cell and Environment, 10: 287-295.

Lloyd, J., Syvertsen, J.P., Kriedemann, P.E. and G.D. Farquhar. 1992. Low conductances for $\mathrm{CO}_{2}$ diffusion from stomata to the sites of carboxylation in leaves of woody spesies. Plant, Cell and Environment, 15: 873-899.

Osborne, B.A. and M.K. Garrett. 1983. Quantum yields for $\mathrm{CO}_{2}$ uptake in some diploid and tetraploid plant species. Plant, Cell and Environment, 6: 135-144.

Oya, V.M. and A.K.H. Laisk. 1976. Adaption of the photosynthesis apparatus to the light profile in the leaf. Soviet Plants Physiology, 23: 381-386. 
The light gradients inside soybean leaves and their effect on the curvature factor - Tania June

Syvertsen, J.P., Lloyd, J., McCnchie, C., Kriedemann, P.E. and G.D. Farquhar. 1995. On the relationship between leaf anatomy and $\mathrm{CO}_{2}$ diffusion through the mesophyll of hypostomatous leaves. Plant, Cell and Environment, 18: 149-157.

Terashima, I. 1986. Dorsiventrality in photosynthetic light response curves of a leaf. Journal of Experimental Botany, 37: 399-405.

Terashima, I. and T. Saeki. 1983. Light environment with leaf 1. Optical properties of paradermal sections of Camellia leaves with special reference to differences in the optical properties of palisade and spongy tissues. Plant Cell Physiology, 24: 1493-1501.

Terashima, I. and T. Saeki. 1985. A new model for leaf photosynthesis incorporating the gradiens of light environment and of photosynthetic properties of chloroplasts within a leaf. Ann. Botany, 56: 489499.

Von Caemmerer, S. and J.R. Evans. 1994. The kinetics of ribulose- 1,5-bisphosphate carboxylase/oxygenase in vivo inferred from measurements of photosynthesis in leaves of transgenic tobacco. Planta, 195: 88-97.

Von Caemmerer, S., Evans, J. R., Hudson, G.S. and T.J. Andrews. 1994. The kinetics of Rubisco inferred from measurements of photosynthesis in leaves of transgenic tobacco with reduced Rubisco content. Planta, 195: 33-47.

Vogelmann, T.C. and L.O. Bjorn. 1984. Measurement of light gradients and spectral regime in plan tissue with a fiber optic probe. Physiol. Plant, 60: 361-368.

Wang, K.Y., Kellomaki, S. and K. Laitinen. 1996. Acclimation of photosynthetic parameter in Scots Pine after three years exposure to elevated temperature and $\mathrm{CO}_{2}$. Agricultural and Forest Meteorology, 82: $195-217$

Wilkins, D., Van Oosten, J. J. and R.T. Besford. 1994. Effects of elevated $\mathrm{CO}_{2}$ on growth and chloroplast protein in Prunus avium. Tree Physiology 14: 769-779. 